\title{
Multimodal Imaging in Rat Model Recapitulates Alzheimer's Disease Biomarkers Abnormalities
}

\author{
Maxime J. Parent, ${ }^{1,2}$ @Eduardo R. Zimmer, ${ }^{1,3,4}$ ๑Monica Shin, ${ }^{1}$ Min Su Kang, ${ }^{1}$ CVladimir S. Fonov, ${ }^{5}$ Axel Mathieu, ${ }^{2}$ \\ Antonio Aliaga, ${ }^{5}$ Alexey Kostikov, ${ }^{5}$ Sonia Do Carmo, ${ }^{6}$ Doris Dea, ${ }^{2}$ 'Judes Poirier, ${ }^{2}$-Jean-Paul Soucy, ${ }^{5}$ \\ Serge Gauthier, ${ }^{1}$ A. Claudio Cuello, ${ }^{6}$ and $\odot$ Pedro Rosa-Neto ${ }^{1,2}$ \\ ${ }^{1} \mathrm{McGill}$ Centre for Studies in Aging, McGill University, Montreal H4H 1R3, Canada, ${ }^{2}$ Douglas Mental Health University Institute, Montreal H4H 1R3, \\ Canada, ${ }^{3}$ Department of Biochemistry, Federal University of Rio Grande do Sul, Porto Alegre 90035-000, Brazil, ${ }^{4}$ Brain Institute (BraIns) of Rio Grande do \\ Sul, Porto Alegre 90610-000, Brazil, ${ }^{5}$ Montreal Neurological Institute, Montreal H3A 2B4, Canada, and ${ }^{6}$ Department of Pharmacology and Therapeutics, \\ McGill University, Montreal H3G 1Y6, Canada
}

Imaging biomarkers are frequently proposed as endpoints for clinical trials targeting brain amyloidosis in Alzheimer's disease (AD); however, the specific impact of amyloid- $\beta(\mathrm{A} \beta)$ aggregation on biomarker abnormalities remains elusive in AD. Using the McGill-RThyl-APP transgenic rat as a model of selective $A \beta$ pathology, we characterized the longitudinal progression of abnormalities in biomarkers commonly used in AD research. Middle-aged (9-11 months) transgenic animals (both male and female) displayed mild spatial memory impairments and disrupted cingulate network connectivity measured by resting-state fMRI, even in the absence of hypometabolism (measured with PET $\left[{ }^{18} \mathrm{~F}\right] \mathrm{FDG}$ ) or detectable fibrillary amyloidosis (measured with PET $\left.\left[{ }^{18} \mathrm{~F}\right] \mathrm{NAV} 4694\right)$ ). At more advanced ages (16-19 months), cognitive deficits progressed in conjunction with resting connectivity abnormalities; furthermore, hypometabolism, $\mathrm{A} \beta$ plaque accumulation, reduction of $\mathrm{CSF} \mathrm{A} \beta_{1-42}$ concentrations, and hippocampal atrophy (structural MRI) were detectable at this stage. The present results emphasize the early impact of $\mathrm{A} \beta$ on brain connectivity and support a framework in which persistent $\mathrm{A} \beta$ aggregation itself is sufficient to impose memory circuits dysfunction, which propagates to adjacent brain networks at later stages.

Key words: Alzheimer; animal model; biomarkers; imaging; MRI; PET

\section{Significance Statement}

The present study proposes a "back translation" of the Alzheimer pathological cascade concept from human to animals. We used the same set of Alzheimer imaging biomarkers typically used in large human cohorts and assessed their progression over time in a transgenic rat model, which allows for a finer spatial resolution not attainable with mice. Using this translational platform, we demonstrated that amyloid- $\beta$ pathology recapitulates an Alzheimer-like profile of biomarker abnormalities even in the absence of other hallmarks of the disease such as neurofibrillary tangles and widespread neuronal losses.

\section{Introduction}

Alzheimer's disease (AD) is characterized by the accumulation of amyloid- $\beta(\mathrm{A} \beta)$ aggregates in various conformations (Glenner and

Received May 17, 2017; revised Oct. 18, 2017; accepted 0ct. 21, 2017.

Author contributions: M.J.P., E.R.Z., J.P., J.-P.S., S.G., A.C.C., and P.R.-N. designed research; M.J.P., E.R.Z., M.S., M.S.K., A.M., A.A., A.K., S.D.C., D.D., and P.R.-N. performed research; V.S.F. contributed unpublished reagents/ analytic tools; M.J.P., E.R.Z., M.S., M.S.K., V.S.F., S.D.C., D.D., and P.R.-N. analyzed data; M.J.P., E.R.Z., M.S., M.S.K., V.S.F., A.M., A.A., A.K., S.D.C., D.D., J.P., J.-P.S., S.G., A.C.C., and P.R.-N. wrote the paper.

This work was supported by the Canadian Institutes of Health Research (CIHR Grant MOP-11-51-31), the Alan Tiffin Foundation, the Alzheimer's Association (Grants NIRG-12-92090 and NIRP-12-259245), and the Fonds de Recherche du Québec Santé (P.R-N.: Chercheur Boursier). J.P., S.G., P.R-N., and A.C.C are members of the CIHR Canadian Consortium of Neurodegeneration in Aging. We thank Eve-Marie Charbonneau for technical support with the animal care, Louise Théroux for ELISA assays, Mirjana Kovacevic for radiochemistry assistance, and Navidea Biopharmaceuticals Inc. for the precursor of $\left[{ }^{8} \mathrm{~F}\right] \mathrm{NAV} 4694$.

The authors declare no competing financial interests.

Correspondence should be addressed to Pedro Rosa-Neto, M.D., Ph.D., Associate Professor, McGill University, 6875 LaSalle Blvd., FBC room 1144, F-0105, Montreal, QC, Canada H4H 1R3. E-mail: pedro.rosa@mcgill.ca.

DOI:10.1523/JNEUROSCI.1346-17.2017
Wong, 1984; Masters et al., 1985; Dickson, 1997; Selkoe, 2001), the occurrence of neurofibrillary tangles (NFTs) composed of hyperphosphorylated tau proteins (Grundke-Iqbal et al., 1986; Kosik et al., 1988; Goedert et al., 1992), and synaptic dysfunction (Masliah et al., 1989; Mufson et al., 2000).

Considering that all of these pathological manifestations are measurable at least several years before the onset of AD clinical symptoms (Jack et al., 2011; Sperling et al., 2011; Bateman et al., 2012; Buchhave et al., 2012; Jansen et al., 2015), increasing attention has been turned toward biomarkers for $\mathrm{AD}$ as measurable proxies of pathophysiological progression, particularly in the presymptomatic stages now referred to as preclinical AD (Dubois

This is an open-access article distributed under the terms of the Creative Commons Attribution License Creative Commons Attribution 4.0 International, which permits unrestricted use, distribution and reproduction in any medium provided that the original work is properly attributed. 
et al., 2016). Most notable among those biomarkers is amyloid deposition in the brain as evidenced by positron emission tomography (PET) with radiopharmaceuticals specific to fibrillary amyloid (Klunk et al., 2004) such as $\left[{ }^{18} \mathrm{~F}\right]$ NAV4694 (Cselényi et al., 2012) and by the reduction of $A \beta$ concentration in the CSF (Shibata et al., 2000; Strozyk et al., 2003; Deane et al., 2008).

In addition, glucose metabolism as measured by $\left[{ }^{18} \mathrm{~F}\right] \mathrm{FDG}$ PET and regional brain volumetry from structural MRI (sMRI) both reveal AD-specific regional patterns of synaptic dysfunction and neurodegeneration (Lehéricy et al., 1994; Minoshima et al., 1997; Silverman et al., 2001; Killiany et al., 2002). Finally, restingstate (task-free) functional MRI (rs-fMRI) has been proposed as an indicator of brain connectivity abnormalities likely due to synaptic dysfunctions (Celone et al., 2006; Sperling et al., 2009). There exists an important colocalization of these disruptions with areas of early preferential deposition of amyloid plaques; both tend to be localized to the default mode network (Klunk et al., 2004; Buckner et al., 2008), primarily involving the precuneus and the posterior cingulate, lateral parietal, and medial prefrontal cortices.

The temporal sequence of biomarker abnormality in $\mathrm{AD}$ has been modeled extensively using cross-sectional data (Jack et al., 2010; Jack and Holtzman, 2013). What remains unclear, however, is the extent to which this progression can be explained by the vulnerability to A $\beta$ toxicity (Alonso et al., 1994; Jagust, 2016). Biomarker studies in animal models expressing a mutated human amyloid precursor protein (hAPP) gene constitute a powerful platform for addressing such questions. To date, however, the literature on $\mathrm{AD}$ imaging biomarkers in transgenic ( $\mathrm{Tg}$ ) animals is composed almost exclusively of research on mice models and has yielded varying and often contradictory results (Kawarabayashi et al., 2001; Bondolfi et al., 2002; Toyama et al., 2005; Maeda et al., 2007; Kuntner et al., 2009; Zimmer et al., 2014). Previously, we showed that this discrepancy is likely due to the diversity of pathological phenotypes across models, the cross-sectional nature of most of these studies, and limited imaging resolution of PET cameras for the mouse brain size (Zimmer et al., 2014).

To test the hypothesis that $\mathrm{A} \beta$ aggregation can itself lead to declines in large-scale brain connectivity, metabolism, and cognitive function, we conducted a longitudinal, multimodal biomarker study using the McGill-R-Thyl-APP Tg rat model of AD-like A $\beta$ pathology, which expresses hAPP with Swedish and Indiana mutations. This model displays progressive $\mathrm{A} \beta$ aggregation and cognitive deficits, but no NFT inclusions or widespread cell death (Leon et al., 2010; Galeano et al., 2014; Wilson et al., 2017). Considering that rat models have a larger and more complex CNS and higher cognitive abilities compared with mice (Do Carmo and Cuello, 2013), they are particularly advantageous for longitudinal preclinical studies involving imaging modalities (Zimmer et al., 2014). Using the McGill-R-Thyl-APP rat model, we designed a longitudinal, multimodal study for quantifying agedependent brain $\mathrm{A} \beta$ deposition (measured with PET $\left[{ }^{18} \mathrm{~F}\right] \mathrm{NAV} 4694$ and CSF $A \beta_{1-42}$ ), progressive synaptic dysfunction (measured with hippocampal volumetry sMRI, rs-fMRI connectivity and PET $\left[{ }^{18} \mathrm{~F}\right] \mathrm{FDG}$ ), and cognitive impairment (measured with a spatial memory task) compared with wild-type (WT) animals.

\section{Materials and Methods}

Procedures. All procedures described here were performed in accordance with the Canadian Council on Animal Care guidelines and were approved by the McGill University Animal Care Ethics Committee.

Experimental design and statistical analysis. A sample of 26 rats (13 WT Wistar, 13 homozygous McGill-R-Thyl-APP; 7 males and 6 females in each group) was used for this project. Tg McGill-R-Thy1-APP rats (gen- erated and bred at the Cuello laboratory of the Department of Pharmacology and Therapeutics, McGill University) express hAPP751 with the Swedish and Indiana mutations under the control of the murine Thy 1.2 promoter, resulting in accumulation of $A \beta$ peptides starting 1 week postnatally, which progress to extracellular plaques at 6-10 months of age in homozygous animals. By 12 months, mature plaques are thioflavin $S$ positive (Leon et al., 2010). Homozygous McGill-R-Thy1-APP also exhibit detectable CSF A $\beta 38,39,40$, and 42 species (Iulita et al., 2014), as well as progressive cognitive deficits (Galeano et al., 2014; Qi et al., 2014; Wilson et al., 2017).

All rats were housed at the Douglas Mental Health University Institute animal facility on a 12/12 h light/darkness cycle and had ad libitum access to food and water. All animals underwent the procedures described below twice: once at a baseline time point (aged 9-11 months old) and one follow-up (16-19 months); imaging modalities of each animal for each time point were acquired within 2-6 weeks.

PET acquisition and processing. PET acquisition was performed using a CTI Concorde R4 microPET for small animals (Siemens Medical Solutions) and two radiotracers: $\left[{ }^{18} \mathrm{~F}\right] \mathrm{NAV} 4694$ for imaging $\mathrm{A} \beta$ and $\left[{ }^{18} \mathrm{~F}\right] \mathrm{FDG}$ for imaging glucose metabolism. For $\left[{ }^{18} \mathrm{~F}\right] \mathrm{NAV} 4694$ scans, anesthesia was first induced using $5 \%$ isoflurane in $0.5 \mathrm{l} / \mathrm{min}$ oxygen and then maintained throughout the procedure with $2 \%$ isoflurane. A 9 min transmission scan using a rotating $\left[{ }^{57} \mathrm{Co}\right]$ point source was followed by a bolus injection of the radiotracer in the tail vein $(13.3 \pm 0.9 \mathrm{MBq}$ in $200 \mu \mathrm{l}$, with a specific activity of $85.97 \pm 46.47 \mathrm{GBq} / \mu \mathrm{mol})$, concomitant with the beginning of the emission scan, which lasted for $60 \mathrm{~min}$ in list mode. The data were then reframed into 27 sequential time frames of increasing durations $(8 \times 30 \mathrm{~s}, 6 \times 1 \mathrm{~min}, 5 \times 2 \mathrm{~min}$, and $8 \times 5 \mathrm{~min})$. For $\left[{ }^{18} \mathrm{~F}\right] \mathrm{FDG}$, tracer injection was done in the tail vein of awake animals $(12.7 \pm 1.1$ $\mathrm{MBq}$ in $200 \mu \mathrm{l}$ ), which were anesthetized (5\% isoflurane in $0.51 / \mathrm{min}$ oxygen for induction, reduced to $2 \%$ during the scan) 50 min later to perform a 20 min emission scan (in a single static time frame) and a 9 min transmission scan. Breathing rate was monitored throughout both scanning procedures; temperature was monitored using a rectal thermometer and maintained at $37 \pm 1^{\circ} \mathrm{C}$ using an electric blanket. Images for both tracers were reconstructed using a maximum a posteriori (MAP) algorithm (voxel size: $0.6 \cdot 0.6 \cdot 1.2 \mathrm{~mm}$ ) and corrected for scatter, dead time, and decay.

MINC tools (www.bic.mni.mcgill.ca/ServicesSoftware) were used for image processing and analysis. Image processing steps are summarized in Figure 1. Briefly, parametric maps were generated. For $\left[{ }^{18} \mathrm{~F}\right] \mathrm{NAV} 4694$, the binding potential $\left(\mathrm{BP}_{\mathrm{ND}}\right)$ was calculated for each voxel using the simplified reference tissue method at the voxel-level (Gunn et al., 1997) with cerebellar gray matter as a reference region. For $\left[{ }^{18} \mathrm{~F}\right] \mathrm{FDG}$, standardized uptake value ratio (SUVr) images were generated by normalizing the tissue radioactivity image using the pons as a reference tissue. Each resulting parametric image was first coregistered to the individual animal's sMRI (see below) using six degrees of freedom (rigid body transformation), then nonlinearly transformed to a standardized rat brain space created from the WT Wistar rats used in the present study to account for differences in brain morphology.

MRI acquisition and processing. MRI acquisition was performed in a 7 T BioSpec 70/30 USR dedicated animal MRI (Bruker) equipped with Avance III electronics and the 500V/300A B-GA12S2 gradient upgrade with a standard $40 \mathrm{~mm}$ quadrature volumetric transceiver. Animals were anesthetized with a $1 \%$ isoflurane/medical air mixture. A constant $37^{\circ} \mathrm{C}$ air flow was used to keep the animals warm.

Structural imaging was obtained using the Bruker standard 3D-True Fast Imaging with Steady State Precession pulse sequence (3D-TrueFISP, a balanced Steady State Free Precession type sequence). To remove banding artifacts, a root-mean-square image of eight phase advance (angles of $0-315$ degrees in increments of 45) acquisitions was obtained. Each TrueFISP phase angle acquisition was acquired as follows: slices oriented in the rostrocaudal axis, FOV of $36 \times 36 \times 36 \mathrm{~mm}$ with a matrix of $180 \times$ $180 \times 180$, TE/TR of $2.5 / 5.0 \mathrm{~ms}$, NEX of 2 , flip angle of $30^{\circ}$, and a bandwidth of $50 \mathrm{kHz}$; no accelerations were used. The resulting image is an average of 16 acquisitions with an isotropic $200 \mu \mathrm{m}$ resolution and was acquired in a total scanning time of $46 \mathrm{~min} 30 \mathrm{~s}$. Hippocampal volumes were measured using manual segmentation performed by an 


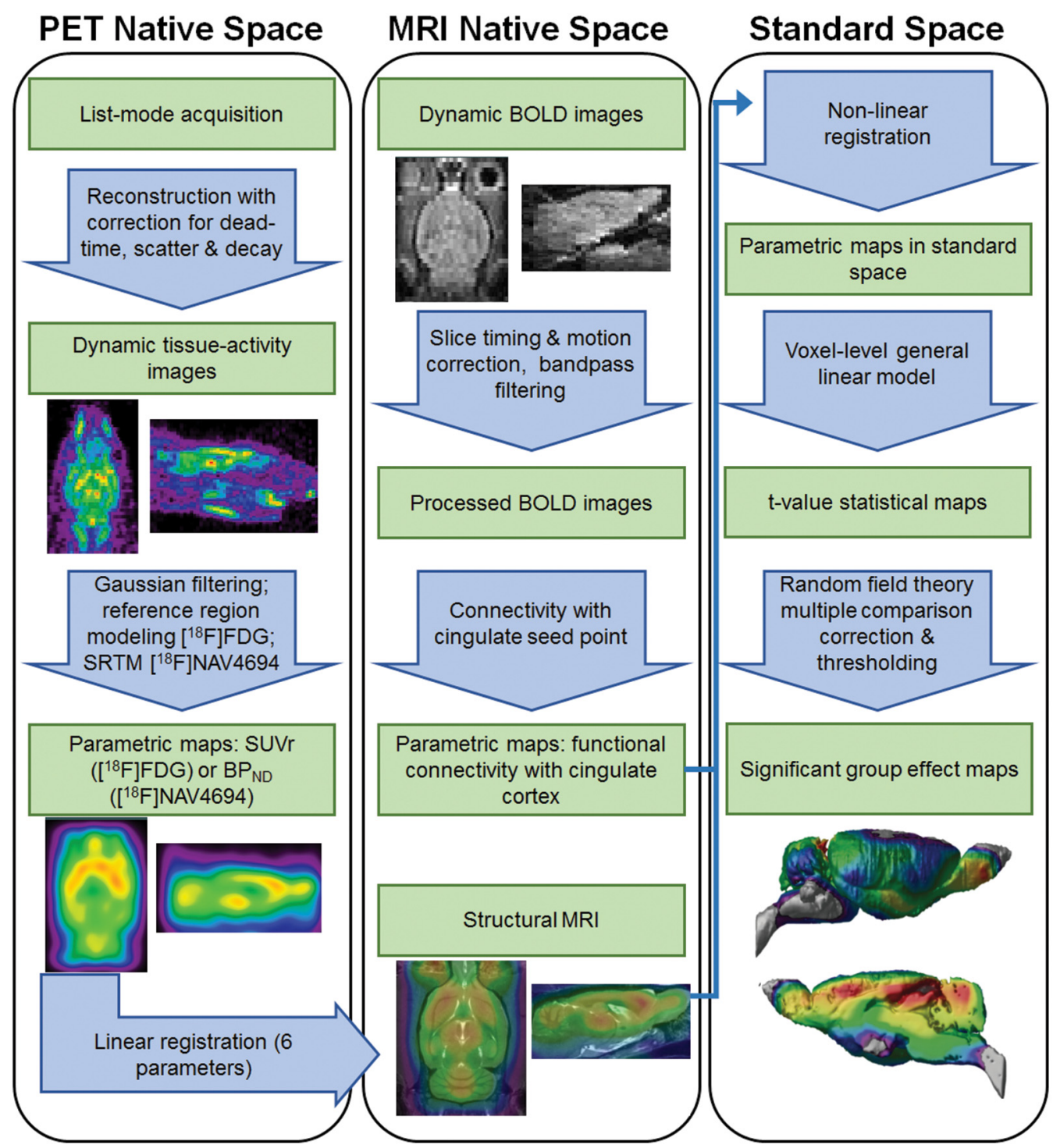

Figure 1. Processing and analytical pipeline for imaging data. PET data were acquired in list mode and then reconstructed with correction for dead time, scatter, and decay. Resulting tissue activity images were filtered with a Gaussian kernel and parametric maps were generated for each radiotracer and then linearly registered to their respective structural (FISP) MRI. For rs-fMRI, dynamic resting-state images were corrected for slice timing and motion and then band-pass filtered. Resulting processed images were correlated at the voxel level to a seed point in the cingulate cortex to generate parametric maps of connectivity. Parametric maps of connectivity, SUVr, and BP ${ }_{\mathrm{ND}}$ in individual MRI space were then nonlinearly coregistered to a standard space consisting of an averaged sMRI. Group effects were assessed with a voxel-level linear model corrected for multiple comparisons using the random field theory approach. SRTM, Simplified reference tissue method.

experimenter blinded to the group conditions and normalized by the intracranial volume.

The rs-fMRI acquisitions were completed immediately after the anatomical scans using the standard Bruker 2D-Spin Echo, Echo Planar pulse sequence (2D-SE-EPI) and the following parameters: slices oriented in the rostrocaudal axis, FOV of $25.6 \times 25.6 \mathrm{~mm}$ with a matrix of $64 \times 64$ and 32 slices of $1.0 \mathrm{~mm}$ for a final resolution of $400 \times 400 \times 1000$ $\mu \mathrm{m}$, interslice distance of $1.0 \mathrm{~mm}, \mathrm{TE} / \mathrm{TR}$ of $15 / 2000 \mathrm{~ms}$, flip angle of $70^{\circ}$, bandwidth of $300 \mathrm{kHz}, 4$ dummy scans to establish steady state, and 450 repetitions for a total scan time of $15 \mathrm{~min}$. A partial-FT acceleration factor of 1.34 ( 16 overscans) was used, with standard fat suppression and 5 standard saturation slices to isolate the brain volume; the fifth saturation band was used over highly fatty throat areas. Finally, the standard EPI navigator was used, along with automatic ghost correction and automatic trajectory adjustment.

The first four volumes $(8 \mathrm{~s})$ were discarded to account for transient drift. Using AFNI (https://afni.nimh.nih.gov), the dynamic functional images were corrected for slice time and motion and then band-pass filtered between 0.01 and $0.15 \mathrm{~Hz}$. Connectivity maps were generated by correlating with a seed point in the cingulate cortex, a component of the rat's default mode network (Lu et al., 2012), which has been shown in this model to be vulnerable to fibrillary $\mathrm{A} \beta$ accumulation (Parent et al., 2013). Resulting images were nonlinearly transformed to the standardized rat brain space.

Spatial memory. The spatial memory of each rat was assessed using the Morris water maze (MWM) (Morris, 1984) over 4 consecutive days, with 4 trials/d, a maximum trial length of $90 \mathrm{~s}$ (rats were placed on the platform after unsuccessful $90 \mathrm{~s}$ trials), and $1 \mathrm{~h}$ between each trial. Each trial was started in a different quadrant and external cues were placed outside the pool for navigation. The time to find the platform was measured automatically using overhead camera tracking with ANY-maze videotracking software (Stoelting) and used as an outcome measure. One hour after the last trial on the fourth day, one probe (no platform) trial to assess reference memory and one visible platform trial was also conducted to account for swim speed and gross visual deficits.

CSF sampling. Under 5\% isoflurane anesthesia, 100-150 $\mu$ l of CSF was collected from each rat through direct puncture of the cisterna magna. Concentrations of $A \beta 1-42$ in the CSF samples were measured using a 

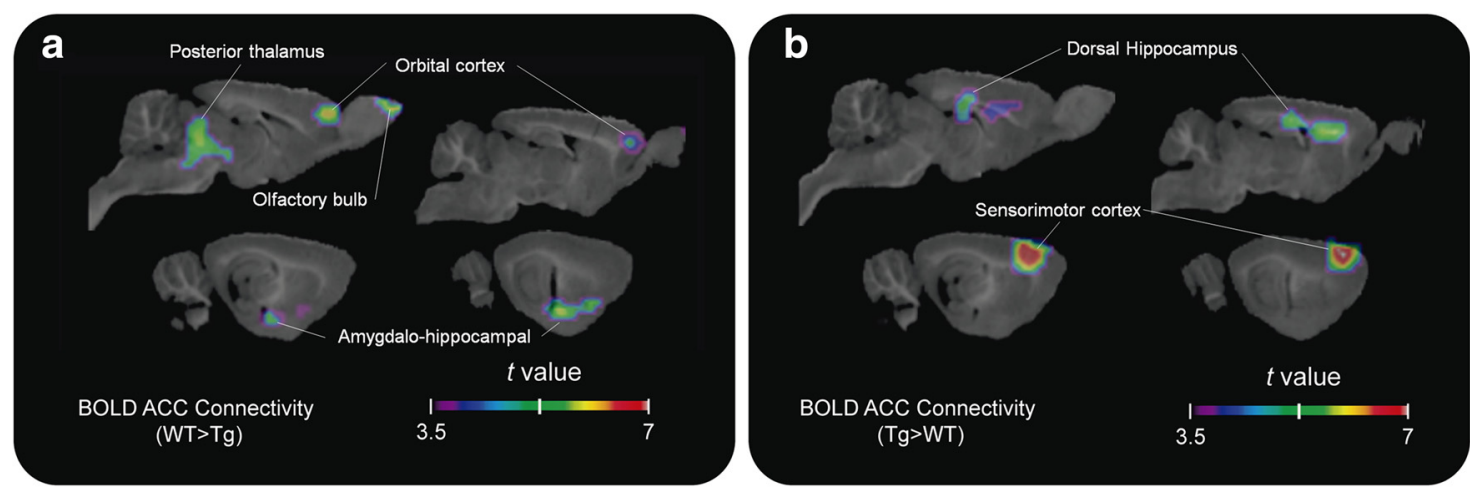

Figure 2. Early functional connectivity disruption in Tg animals. $t$-statistical rs-fMRI connectivity group contrasts ( $n=13$ animals per group) at baseline are shown overlaid on a template structural image (sagittal slices 1-4 mm lateral to midline at $1 \mathrm{~mm}$ intervals). $\boldsymbol{a}, \boldsymbol{b}$, Connectivity with the cingulate seed point is reduced for Tg rats in the orbital cortex, thalamus, and amygdalohippocampal area $(\boldsymbol{a})$, and upregulated in the dorsal hippocampus and primary sensory and motor cortical regions $(\boldsymbol{b})$. Clusters of at least $30 \mathrm{~mm}^{3}$ are shown for values corresponding to $p<0.05$ after multiple-comparisons correction.

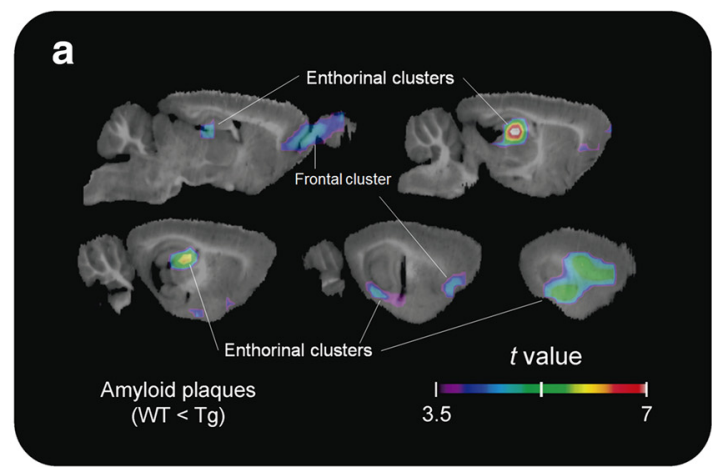

b
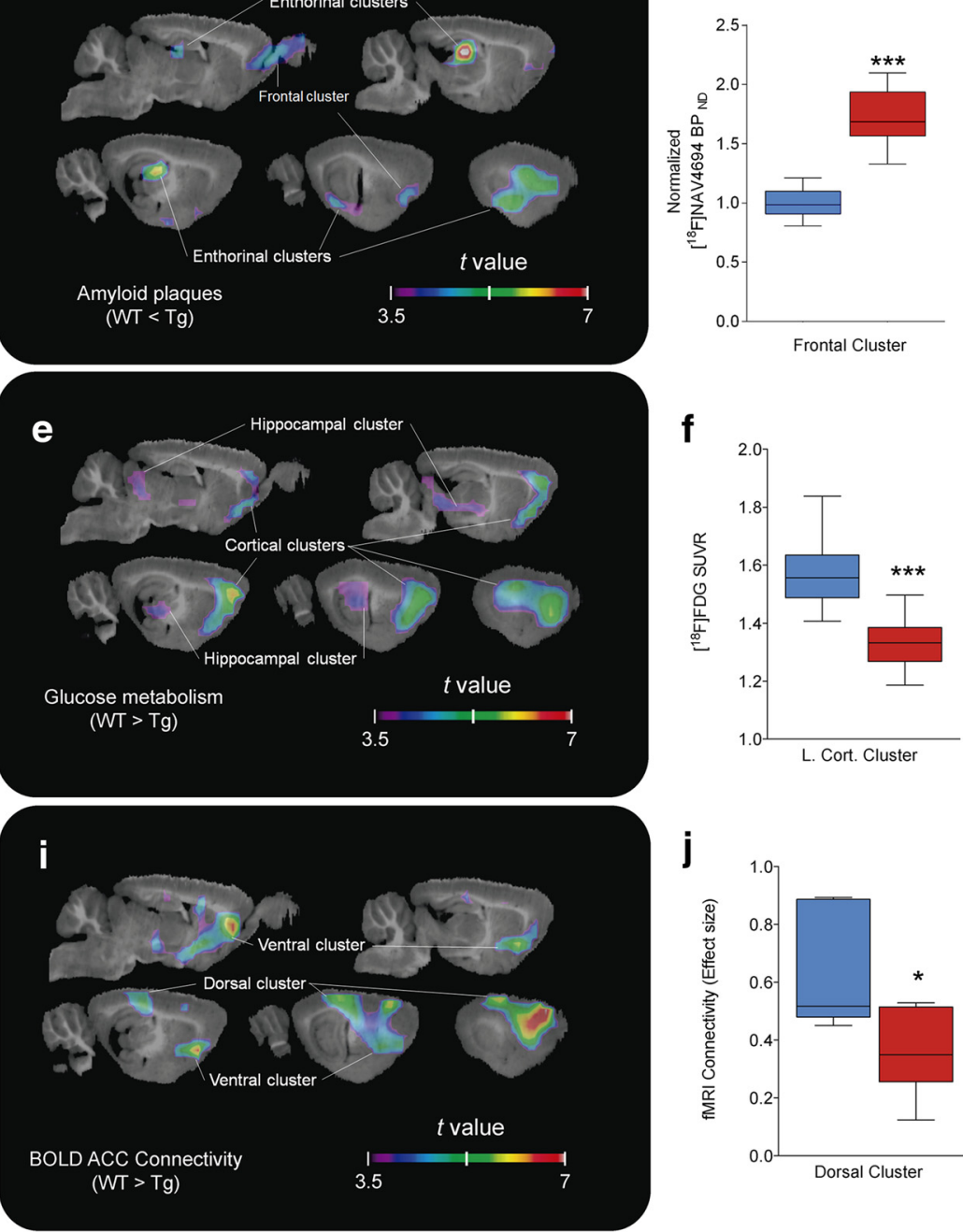

f

C

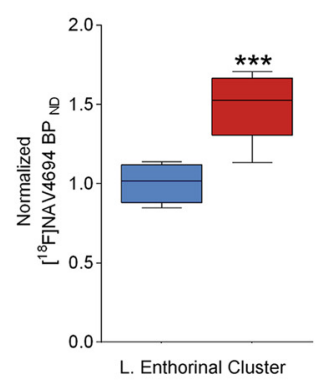

g

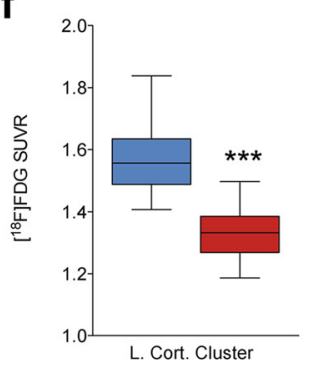

j

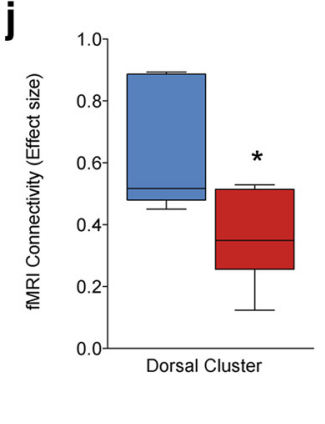

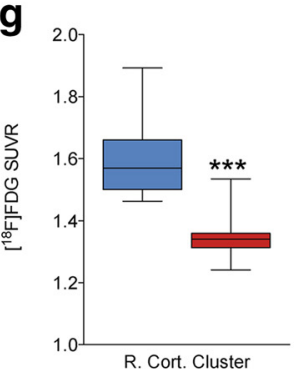

h

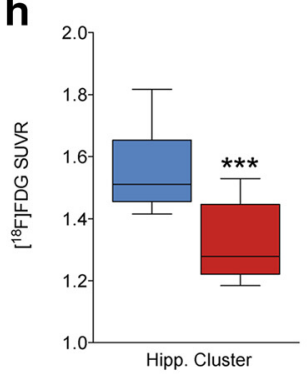

Figure 3. Amyloid plaques, glucose hypometabolism, and functional connectivity impairments in $\mathrm{Tg}$ animals. $t$-statistical group contrasts at follow-up time point are shown overlaid on a template structural image. Significant group contrasts after multiple comparison correction in clusters of at least $30 \mathrm{~mm}^{3}$ are projected on sagittal slices $(1-5 \mathrm{~mm}$ lateral from midline at $1 \mathrm{~mm}$ intervals). Box-and-whisker plots show the distribution of the parametric measures for each cluster in WT (blue) and Tg (red) animals. $\boldsymbol{a}-\boldsymbol{d}\left[{ }^{18} \mathrm{~F}\right] \mathrm{NAV} 4694 \mathrm{BP} \mathrm{ND}_{\mathrm{N}}(\boldsymbol{n}=10 \mathrm{Tg}, 9$ WT; $\boldsymbol{a})$ is significantly higher for Tg rats in the olfactory bulb and frontal cortex $(\boldsymbol{b})$ and in the left (c) and right (d) dorsal hippocampus and the entorhinal and insular cortices. $\boldsymbol{e}-\boldsymbol{h},\left[{ }^{18} \mathrm{~F}\right] \mathrm{FDG}$ uptake $(n=10 \mathrm{Tg}, 9 \mathrm{WT} ; \boldsymbol{e})$ is lower in Tg rats across the left $(\boldsymbol{f})$ and right $(\boldsymbol{g})$ frontal cortex and in the genu of the hippocampus, ventral thalamic nuclei, and colliculi $(\boldsymbol{h})$. $\boldsymbol{i}-\boldsymbol{k}$, rs-fMRI $(n=8 \mathrm{Tg}, 8 \mathrm{WT}$; $\boldsymbol{i})$ connectivity is weaker in dorsal hippocampus and the retrosplenial cortex $(\boldsymbol{j})$ as well as in prelimbic areas and the basal forebrain $(\boldsymbol{k}){ }^{*{ }^{* *}} p<0.0005 ;{ }^{*} p<0.05$. 
a
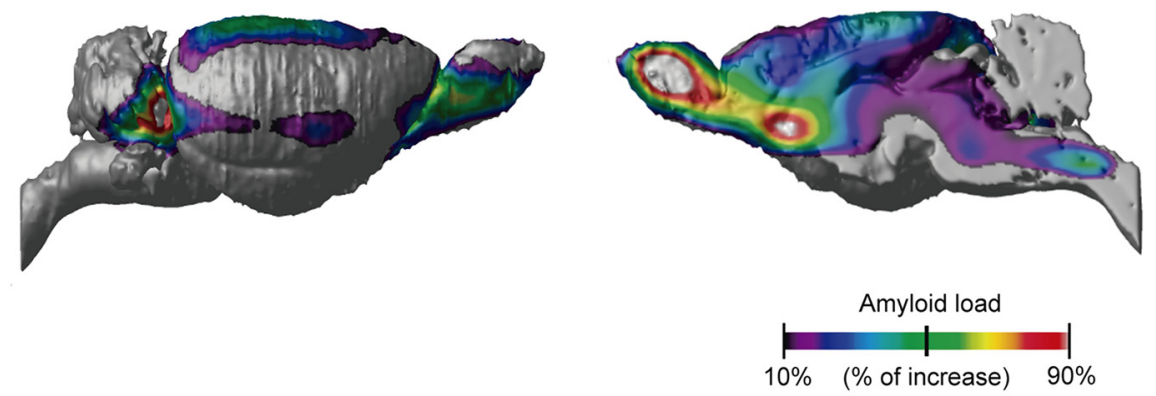

b
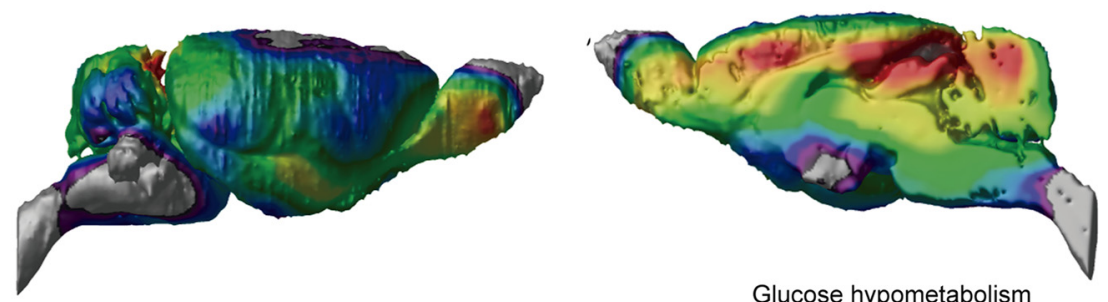

Glucose hypometabolism

$10 \% \quad$ (\% of decrease) $\quad 40 \%$

Figure 4. Regional progression of amyloid plaques and glucose hypometabolism over time. Percentage change values overlaid on a brain surface and midsagittal projections. Longitudinal progression of PET biomarkers in $\mathrm{Tg}$ animals over a 6 month period ( $n=10$ animals with two time point measurements per biomarker) is shown. $a,\left[{ }^{18} \mathrm{~F}\right] \mathrm{NAV} 4694$ binding increase over time is most prominent in the parietal and entorhinal cortices and in the basal forebrain and olfactory bulb. $\boldsymbol{b},\left[{ }^{18} \mathrm{~F}\right] \mathrm{FDG}$ uptake longitudinal decreases are present throughout the encephalon, with the highest changes across the cortical mantle and in the cerebellum.

\section{$A \boldsymbol{\beta}$ accumulation induces time- dependent changes in glucose metabolism and connectivity}

We first examined the consequences of incremental aggregation of $\mathrm{A} \beta$ in the McGill-R-Thy1-APP Tg rat model of $\mathrm{AD}$-like $\mathrm{A} \beta$ pathology by PET and rsfMRI. Although some fibrillary $A \beta$ is visible by immunohistochemistry at the baseline time point (9-11 months), especially in the dorsal hippocampus (see Fig. 6b), no significant group difference in $\left[{ }^{18} \mathrm{~F}\right]$ NAV4694 binding was found at that age. Similarly, glucose metabolism as measured by $\left[{ }^{18} \mathrm{~F}\right] \mathrm{FDG}$ uptake was not significantly altered in younger $\mathrm{Tg}$ animals. Group contrast for rs-fMRI showed clusters of significantly lower cingulate connectivity in the Tg group centered on the orbital cortex and the thalamus $(k=34.74$ $\mathrm{mm}^{3}$, peak $\left.t_{(24)}=6.528, p<0.0001\right)$, as well as higher connectivity with the dorsal hippocampus and sensorimotor cortical areas (Fig. 2).

At the follow-up time point (16-19 months of age), all three imaging outcomes showed significant group differences (Fig. 3). For PET A $\beta$ load, the Tg group had significantly higher binding in a cluster covering the olfactory bulb and the infralimbic cortex and spreading lat-

multiplex xMAP Luminex platform with the ELISA kit INNOTEST

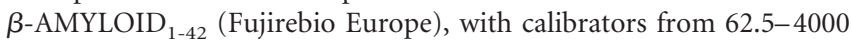
$\mathrm{pg} / \mathrm{ml}$.

Immunohistochemistry. After completion of the second time point experiments, rats were anesthetized using equithesin (pentobarbitol based, $2.5 \mathrm{ml} / \mathrm{kg}$, i.p.) before transcardiac perfusion with cold $0.1 \mathrm{M}$ phosphate buffer $(\mathrm{PB}), \mathrm{pH}$ 7.4. The brains were removed, divided into hemispheres, postfixed in $4 \%$ paraformaldehyde in $0.1 \mathrm{M} \mathrm{PB}$ for $24 \mathrm{~h}$ at $4^{\circ} \mathrm{C}$, and then equilibrated in a solution of $30 \%$ sucrose in $0.1 \mathrm{M} \mathrm{PB}$. Coronal sections of $40 \mu \mathrm{m}$ thickness were obtained using a freezing sledge microtome (SM 2000R; Leica). Free-floating sections (3 per animal) were collected in PBS containing $10 \mathrm{~mm} \mathrm{Na}_{2} \mathrm{HPO}_{4}, 150 \mathrm{~mm} \mathrm{NaCl}$, and $2.7 \mathrm{~mm} \mathrm{KCl}$ and processed for immunohistochemistry. Brain sections were incubated first in McSA1 (MediMabs), a mouse monoclonal antibody detecting human $\mathrm{A} \beta$ (Grant et al., 2000), and then in goat anti-mouse antibody (MP Biochemicals), followed by a mouse anti-peroxidase monoclonal antibody complex (MAP/HRP complex; MediMabs), and developed using $3,3^{\prime}$-diaminobenzidine as the chromogen (Vector Laboratories). Images of $\mathrm{A} \beta$ immunoreactivity were acquired using a Zeiss microscope equipped with an AxioCam HRc digital camera (Carl Zeiss) and Axiovision 4.8 software.

Statistical analyses. For imaging outcome measures $\left(\left[{ }^{18} \mathrm{~F}\right] \mathrm{NAV} 4694\right.$, $\left[{ }^{18} \mathrm{~F}\right]$ FDG and rs-fMRI), group effects were estimated using a voxellevel general linear model. Resulting $t$-statistical maps were corrected for multiple comparisons using a random field theory-based approach (Worsley et al., 1996) for an adjusted threshold of $p<0.05$ in clusters of at least $30 \mathrm{~mm}^{3}$. Longitudinal changes in $\left[{ }^{18} \mathrm{~F}\right] \mathrm{NAV} 4694$ binding and $\left[{ }^{18} \mathrm{~F}\right] \mathrm{FDG}$ uptake were measured with the voxel-level differences between baseline and follow-up parametric images, normalized by the baseline, and expressed as maps of average percentage changes.

\section{Results}

No significant effect of sex was found for any measurement; therefore, males and females were grouped together for all subsequent analyses. erally to the insular, perirhinal, and entorhinal cortices $(k=$ $113.34 \mathrm{~mm}^{3}$, peak $\left.t_{(17)}=6.659, p<0.0001\right)$, in which the ratio of $\mathrm{BP}_{\mathrm{ND}}$ in the Tg group compared with the nonspecific binding observed in WT animals was $1.734 \pm 0.428$. A second cluster covering the dorsal hippocampi, the caudal piriform cortex, and amygdala $\left(k=70.24 \mathrm{~mm}^{3}\right.$, peak $\left.t_{(17)}=7.854, p<0.0001\right)$ showed an average ratio of $1.767 \pm 0.467$ (Fig. $3 a-d$ ).

Group contrast of $\left[{ }^{18} \mathrm{~F}\right] \mathrm{FDG}$ PET hypometabolism revealed 2 symmetrical clusters of significant differences where the WT group had higher uptake than Tg animals $(t>3.58)$, located in the ventral orbital, secondary motor, cingulate, prelimbic, barrel, and entorhinal cortices (left hemisphere: $k=133.09$, peak $t_{(17)}=$ 6.46, $p<0.0001$; average SUVr of $1.449 \pm 0.157$ for WT and $1.343 \pm 0.14$ for Tg; right hemisphere: $k=117.48 \mathrm{~mm}^{3}$, peak $t_{(17)}=6.403, p<0.0001$; SUVr of $1.484 \pm 0.123$ for WT and $1.369 \pm 0.099$ for $\mathrm{Tg}$ ). A third, median cluster covered the ventral thalamus and medial geniculate, as well as the hippocampal genus and the inferior colliculi $\left(k=82.36 \mathrm{~mm}^{3}\right.$, peak $t_{(17)}=4.417$, $p=0.0004)$, where the WT group had an average SUVr of $1.448 \pm 0.121$ compared with $1.343 \pm 0.112$ for the Tg group (Fig. $3 e-h)$.

Connectivity with the cingulate seed point, as measured by rs-fMRI, was lower in Tg animals, including the prelimbic and infralimbic cortices, basal forebrain, ventral caudate putamen, dorsal hippocampi, parietal association cortex, and endopiriform nucleus $\left(k=242.442 \mathrm{~mm}^{3}\right.$, peak $\left.t_{(15)}=7.392, p<0.0001\right)$ (Fig. 3i-k).

In terms of age effect, the Tg but not the WT group showed a progressive increase of fibrillary $\mathrm{A} \beta$, with $\left[{ }^{18} \mathrm{~F}\right] \mathrm{NAV} 4694 \mathrm{BP}_{\mathrm{ND}}$ reaching differences of up to $47.44 \%$ in the parietal association and retrosplenial cortices, $91.22 \%$ in the caudal entorhinal cortex, and $94.08 \%$ in the basal forebrain and olfactory bulb (Fig. $4 a$ ). Conversely, $\left[{ }^{18} \mathrm{~F}\right]$ FDG uptake decreases (Fig. $4 b$ ) were ob- 
served throughout the brain in $\mathrm{Tg}$ animals, with the highest reductions located in frontal (38\%) and parietal (37\%) cortices as well as the cerebellum (36\%). Together, these findings suggest that $A \beta$ deposition per se is sufficient to cause abnormalities in glucose metabolism and connectivity.

\section{$\mathrm{A} \boldsymbol{\beta}$-induced functional deficits are reflected by spatial memory impairments}

Spatial memory, as tested using the MWM task, showed a learning effect for both groups at both time points, shown as the latency to locate the platform in the learning phase of the task from days 1-4 (Fig. 5). For the baseline time point, there was a significant genotype effect only on the fourth day of testing, with the WT taking significantly less time to locate the platform than the Tg animals $(F=8.996, p=0.007)$. At followup, the WT group performed significantly better than $\mathrm{Tg}$ for both the third $(F=5.903$, $p=0.028)$ and fourth $(F=5.352, p=$ 0.038 ) days of learning. In addition, both groups performed significantly better on the first day of testing at follow-up than they did at baseline $(F=8.243, p=0.001)$. Despite the differences during the learning phase, both groups reached comparable performance during the probe trial as measured by proportion of time spent in the target quadrant (WT: $38.9 \pm 14.9 \%$; Tg: $39.9 \pm 9.5 \%$ ). Latency to reach the platform during a trial where the platform was visible did not differ significantly between $\operatorname{Tg}(17 \pm 10.4 \mathrm{~s})$ and WT (14.4 $\pm 5.2 \mathrm{~s})$. These findings illustrate observable cognitive impairments as a consequence of $\mathrm{A} \beta$-induced metabolic and synaptic dysfunctions.

\section{$\mathrm{A} \boldsymbol{\beta}$ deposition in the brain is reflected by decreased $\mathrm{A} \boldsymbol{\beta}$ CSF levels and brain volume}

Last, two other common AD biomarkers, hippocampal volumetry and CSF A $\beta 1-42$, were studied using the McGill-R-Thyl-APP model. The normalized hippocampal volumes of $\mathrm{Tg}$ animals decreased from $79.606 \pm 3.093 \mathrm{~mm}^{3}$ at baseline to $73.283 \pm 3.93$ at follow-up (paired $t_{(8)}=6.328, \mathrm{p}=0.0002$ ), whereas there was no significant age effect for WT rats (Fig. 6a,c). In addition, the CSF A $\beta 1-42$ concentrations in older $\mathrm{Tg}$ rats decreased by $28.44 \%$ compared with the first time point assay (Fig. 6d), from $2002.507 \pm$ $453.008 \mathrm{pg} / \mathrm{ml}$ at baseline to $1433.031 \pm 273.349 \mathrm{pg} / \mathrm{ml}$ at follow-up (paired $t_{(8)}=4.513, p=0.002$ ), with overall concentrations being comparable to those observed in elderly human cohorts (Fig. 6e).

\section{Discussion}

In summary, we have shown in this longitudinal study that $\mathrm{A} \beta$ aggregates secondary to the expression of mutated hAPP in the rat brain (devoid of NFTs or widespread neuronal depletion) are sufficient to cause specific brain injury quantifiable using the same biomarkers that are used as outcome measures in $\mathrm{AD}$ clinical studies. In aged McGill-R-Thy1-APP rats, amyloidosis was observed by increased $\left[{ }^{18} \mathrm{~F}\right] \mathrm{NAV} 4694$ binding in addition to decreased CSF A $\beta_{1-42}$ concentrations. Compared with WT controls, the Tg animals showed progressive functional decline, reflected by reduced resting brain connectivity and glucose metabolism, as well as spatial memory impairments measured by the MWM task.

Interestingly, both rs-fMRI and behavioral measures showed abnormalities before mature fibrillary plaques or glucose hypometabolism were detectable by microPET imaging. These results support the notion that human $A \beta$ oligomeric aggregates exert toxic effects before the formation of mature, thioflavin-positive $A \beta$ plaques (Walsh et al., 2002; Forny-Germano et al., 2014). Indeed, previous electrophysiological studies conducted in the McGill-R-Thy1APP and other models of human brain amyloidosis conducted at this disease stage suggest that early brain connectivity changes or memory declines observed in our cohort are conceivably functional consequences of synaptic alterations (Iulita et al., 2014; Qi et al., 2014; Wilson et al., 2017).

As suggested previously, adaptations of network architecture such as recruitment and strengthening or weakening of specific connections might occur as a consequence of $A \beta$ aggregates (Greicius et al., 2004; Buckner et al., 2009; Gardini et al., 2015). In fact, the brain network 


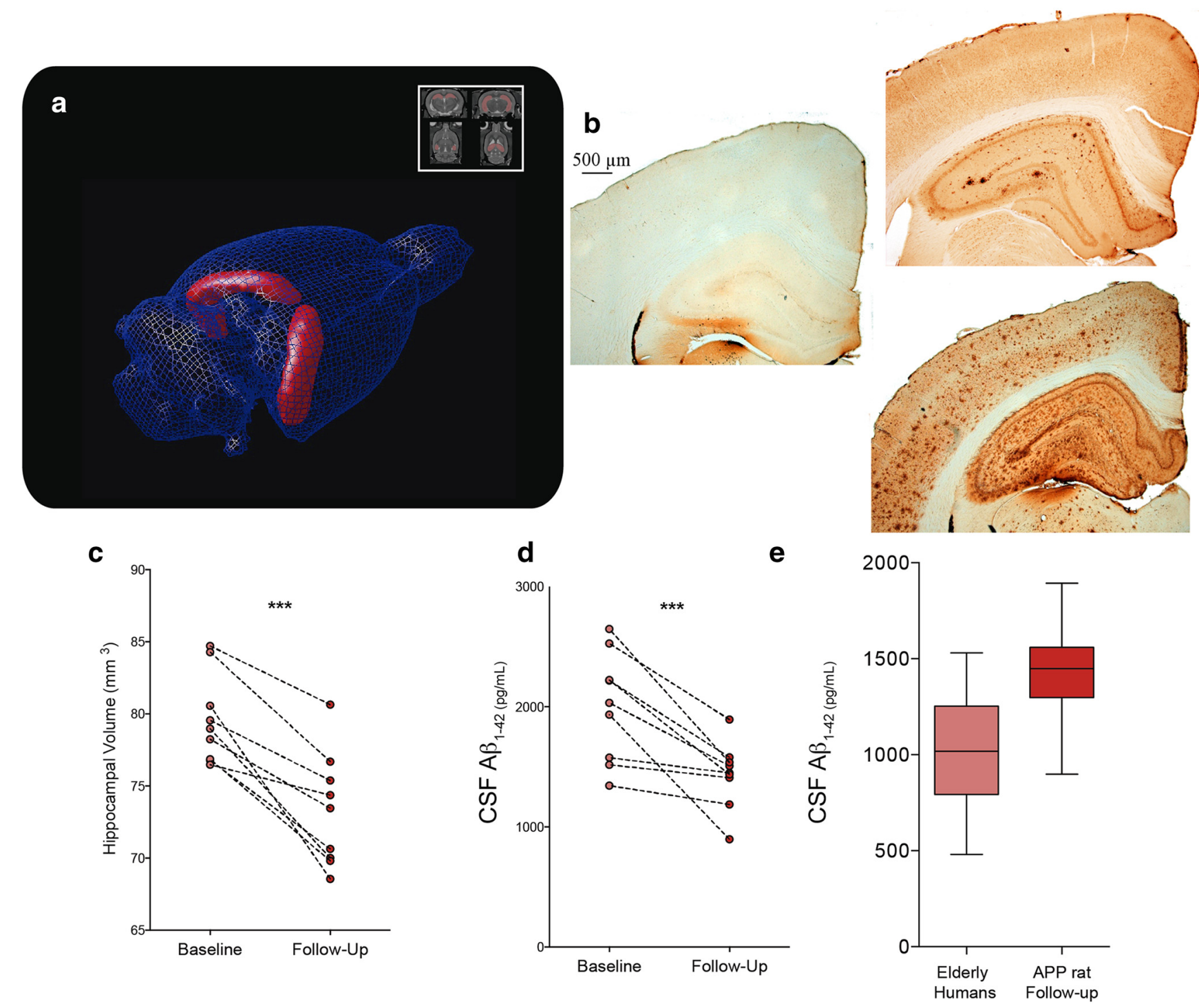

Figure 6. Hippocampal volumetry and CSF A $\beta 1-42$ concentrations. $\boldsymbol{a}, \boldsymbol{c}$, Volumetric analysis of the hippocampus after manual segmentation showing average decrease of normalized volume from 79.606 to $73.283 \mathrm{~mm}^{3}$ (7.94\% lower) in Tg animals, with individual trajectories ( $n=8$ animals with two time point measurements) of hippocampal volume between baseline and follow-up. $\boldsymbol{b}, A \beta$ immunoreactivity detection using McSA1 antibody in the brain tissue of representative WT (left) and Tg animals at 11 (top right) and 20 months of age (bottom right). Slices are $3.3 \mathrm{~mm}$ posterior from bregma, showing the dorsal hippocampus and the retrosplenial, somatosensory, and auditory cortices. $\boldsymbol{d}$, Individual trajectories $(n=8$ animals with 2 time point measurements) of CSF concentrations of A $\beta 1-42$ between baseline and follow-up for Tg rats. Concentrations went from an average of 2002.507 to $1433.031 \mathrm{pg} / \mathrm{ml}$, representing a $28.44 \%$ decrease. $\boldsymbol{e}$, Distribution of CSF concentrations of $A \beta 1-42$ in elderly humans $(n=62,75.5 \pm 6.8$ years old $)$ compared with those of Tg rats at the follow-up time point $(n=8) .{ }^{* * *} p<0.0005$.

abnormalities reported here possibly represent a large-scale signature of $\mathrm{A} \beta$-induced synaptic dysfunction rather than disruption of the underlying structural connections (Lacor et al., 2007; Bao et al., 2012). Remarkably, the fact that human $A \beta$ aggregates enhance the connectivity between hippocampus and cingulate cortex in the animal model and in mildly cognitively impaired patients indicates susceptibility of this specific memory network component to $\mathrm{A} \beta$ (Bai et al., 2009; Elman et al., 2014; Gardini et al., 2015). In fact, early functional deficits preceding the onset of fibrillary $\mathrm{A} \beta$ are possibly related to synaptic vulnerabilities, which supports the concept that localized $\mathrm{A} \beta$ deposition may be dependent on the default patterns of activity preceding disease onset (Buckner et al., 2005). It should be noted that, although these early functional changes underscore deleterious effects of pre-plaque $\mathrm{A} \beta$ aggregates, we cannot discard the possibility that further damage is imposed by fibrillary $\mathrm{A} \beta$ deposits in later disease stages.

Although the progression rates of biomarker abnormalities over time vary significantly throughout the brain, both amy- loidosis and hypometabolism are contained within a range of $20-40 \%$ in the frontoparietal areas between the cingulate and retrosplenial cortices. Specifically, in the parietal association and retrosplenial cortices, fibrillary $\mathrm{A} \beta$ deposition increased by an average of $34 \%$ over the 6 month period separating baseline and follow-up scans, whereas glucose metabolism decreased by an average of $31 \%$. This characteristic glucose hypometabolism indicates synaptic dysfunction, which can be attributed both to neuronal or astrocytic dysfunction (Zimmer et al. 2017).

Colocalization among A $\beta$ fibrillary deposition, hypometabolism, and connectivity decline occurred in the vicinity of the rhinal fissure encompassing the somatosensory and limbic cortices, whereas other brain regions showed partial biomarker abnormality overlapping. For instance, both fibrillary $\mathrm{A} \beta$ and connectivity impairments converge in cortical and hippocampal regions, which confirms that $A \beta$ is sufficient to predict functional connectivity decreases in resting-state networks and in the hip- 
pocampal formation in humans (Hedden et al., 2009). Conversely, whereas progressive accumulation of fibrillary $\mathrm{A} \beta$ was most prominent in the olfactory bulb and basal forebrain, decreases in glucose uptake was largest in the cortex. This regional dissociation likely reflects a selective vulnerability of these cortical areas to $A \beta$ toxicity or could be explained by a downregulation of the basalo-cortical projections. Indeed, regional declines in metabolism measurable with $\left[{ }^{18} \mathrm{~F}\right]$ FDG PET can be induced by an injury in a remote brain region (Meguro et al., 1999).

The basal $\mathrm{A} \beta_{1-42}$ levels observed in these animals are comparable to those in human populations (Fig. $6 d$ ), which underlines the translational value of the present observations. Mild brain atrophy measured with sMRI indicated a modest but significant effect of $\mathrm{A} \beta$ on volumetry limited to the hippocampus, which is the only structure where cell death is observed in McGill-R-Thy1APP rats (Heggland et al., 2015). Resilience of the surrounding cortical areas to atrophy might be explained by the absence of NFTs because native murine hyperphosphorylated tau is not prone to aggregation. Alternatively, the follow-up time point of this study may not have been late enough for the initiation of more pronounced brain atrophy. Future studies of this model will investigate CSF levels of hyperphosphorylated tau to gain a better understanding of the progression of pre-atrophy neurodegeneration. Finally, the early memory impairment observed here seems to contrast with the human sequence of biomarkers abnormalities modeled by Jack and Holtzman (2013), which could be explained by an absence of neural reserve in the less evolved rodent CNS. Learning deficits were also observed for a visual association task in this animal model (Wilson et al., 2017), whereas hemizygous Tg animals ( \pm ) showed impairments in working memory as early as 6 months of age (Galeano et al., 2014).

Our findings indicate that longitudinal biomarker acquisitions in rodents recapitulate large-scale observational and interventional studies in humans, specifically in prodromal and early stages of the disease. This is the first longitudinal, multiparametric study using a robust rat model of $\mathrm{A} \beta$ pathology illustrating progressive abnormalities in $\mathrm{AD}$ biomarkers. With only a single transgene insertion site per allele, this rat model has minimal genetic invasion compared with other animal models, yet was able to reproduce a biomarker profile closely analogous to that of human disease. Based on the present observations, we propose that biomarker abnormalities as a function of $\mathrm{A} \beta$ pathology are more evident at the level of large-scale brain network connectivity and regional brain metabolism measurements than at that of brain atrophy or memory impairment measurements.

\section{References}

Alonso AC, Zaidi T, Grundke-Iqbal I, Iqbal K (1994) Role of abnormally phosphorylated tau in the breakdown of microtubules in Alzheimer disease. Proc Natl Acad Sci U S A 91:5562-5566. CrossRef Medline

Bai F, Watson DR, Yu H, Shi Y, Yuan Y, Zhang Z (2009) Abnormal restingstate functional connectivity of posterior cingulate cortex in amnestic type mild cognitive impairment. Brain Res 1302:167-174. CrossRef Medline

Bao F, Wicklund L, Lacor PN, Klein WL, Nordberg A, Marutle A (2012) Different beta-amyloid oligomer assemblies in Alzheimer brains correlate with age of disease onset and impaired cholinergic activity. Neurobiol Aging 33:825.e1-e13. Medline

Bateman RJ, et al. (2012) Clinical and biomarker changes in dominantly inherited Alzheimer's disease. N Engl J Med 367:795-804. CrossRef Medline

Bondolfi L, Calhoun M, Ermini F, Kuhn HG, Wiederhold KH, Walker L, Staufenbiel M, Jucker M (2002) Amyloid-associated neuron loss and gliogenesis in the neocortex of amyloid precursor protein transgenic mice. J Neurosci 22:515-522. Medline

Buchhave P, Minthon L, Zetterberg H, Wallin AK, Blennow K, Hansson O (2012) Cerebrospinal fluid levels of beta-amyloid 1-42, but not of tau, are fully changed already 5 to 10 years before the onset of Alzheimer dementia. Arch Gen Psychiatry 69:98-106. CrossRef Medline

Buckner RL, Snyder AZ, Shannon BJ, LaRossa G, Sachs R, Fotenos AF, Sheline YI, Klunk WE, Mathis CA, Morris JC, Mintun MA (2005) Molecular, structural, and functional characterization of Alzheimer's disease: evidence for a relationship between default activity, amyloid, and memory. J Neurosci 25:7709-7717. CrossRef Medline

Buckner RL, Andrews-Hanna JR, Schacter DL (2008) The brain's default network: anatomy, function, and relevance to disease. Ann N Y Acad Sci 1124:1-38. CrossRef Medline

Buckner RL, Sepulcre J, Talukdar T, Krienen FM, Liu H, Hedden T, AndrewsHanna JR, Sperling RA, Johnson KA (2009) Cortical hubs revealed by intrinsic functional connectivity: mapping, assessment of stability, and relation to Alzheimer's disease. J Neurosci 29:1860-1873. CrossRef Medline

Celone KA, Calhoun VD, Dickerson BC, Atri A, Chua EF, Miller SL, DePeau K, Rentz DM, Selkoe DJ, Blacker D, Albert MS, Sperling RA (2006) Alterations in memory networks in mild cognitive impairment and Alzheimer's disease: an independent component analysis. J Neurosci 26 : 10222-10231. CrossRef Medline

Cselényi Z, Jönhagen ME, Forsberg A, Halldin C, Julin P, Schou M, Johnström P, Varnäs K, Svensson S, Farde L (2012) Clinical validation of 18F-AZD4694, an amyloid-beta-specific PET radioligand. J Nucl Med 53:415-424. CrossRef Medline

Deane R, Sagare A, Zlokovic BV (2008) The role of the cell surface LRP and soluble LRP in blood-brain barrier Abeta clearance in Alzheimer's disease. Curr Pharm Des 14:1601-1605. CrossRef Medline

Dickson DW (1997) The pathogenesis of senile plaques. J Neuropathol Exp Neurol 56:321-339. CrossRef Medline

Do Carmo S, Cuello AC (2013) Modeling Alzheimer's disease in transgenic rats. Mol Neurodegener 8:37. CrossRef Medline

Dubois B, et al. (2016) Preclinical Alzheimer's disease: Definition, natural history, and diagnostic criteria. Alzheimers Dement 12:292-323. CrossRef Medline

Elman JA, Oh H, Madison CM, Baker SL, Vogel JW, Marks SM, Crowley S, O'Neil JP, Jagust WJ (2014) Neural compensation in older people with brain amyloid-beta deposition. Nat Neurosci 17:1316-1318. CrossRef Medline

Forny-Germano L, Lyra e Silva NM, Batista AF, Brito-Moreira J, Gralle M, Boehnke SE, Coe BC, Lablans A, Marques SA, Martinez AM, Klein WL, Houzel JC, Ferreira ST, Munoz DP, De Felice FG (2014) Alzheimer's disease-like pathology induced by amyloid-beta oligomers in nonhuman primates. J Neurosci 34:13629-13643. CrossRef Medline

Galeano P, Martino Adami PV, Do Carmo S, Blanco E, Rotondaro C, Capani F, Castaño EM, Cuello AC, Morelli L (2014) Longitudinal analysis of the behavioral phenotype in a novel transgenic rat model of early stages of Alzheimer's disease. Front Behav Neurosci 8:321. Medline

Gardini S, Venneri A, Sambataro F, Cuetos F, Fasano F, Marchi M, Crisi G, Caffarra P (2015) Increased functional connectivity in the default mode network in mild cognitive impairment: a maladaptive compensatory mechanism associated with poor semantic memory performance. J Alzheimers Dis 45:457-470. CrossRef Medline

Glenner GG, Wong CW (1984) Alzheimer's disease and Down's syndrome: sharing of a unique cerebrovascular amyloid fibril protein. Biochem Biophys Res Commun 122:1131-1135. CrossRef Medline

Goedert M, Spillantini MG, Cairns NJ, Crowther RA (1992) Tau proteins of Alzheimer paired helical filaments: abnormal phosphorylation of all six brain isoforms. Neuron 8:159-168. CrossRef Medline

Grant SM, Ducatenzeiler A, Szyf M, Cuello AC (2000) Abeta immunoreactive material is present in several intracellular compartments in transfected, neuronally differentiated, P19 cells expressing the human amyloid beta-protein precursor. J Alzheimers Dis 2:207-222. CrossRef Medline

Greicius MD, Srivastava G, Reiss AL, Menon V (2004) Default-mode network activity distinguishes Alzheimer's disease from healthy aging: evidence from functional MRI. Proc Natl Acad Sci U S A 101:4637-4642. CrossRef Medline

Grundke-Iqbal I, Iqbal K, Quinlan M, Tung YC, Zaidi MS, Wisniewski HM (1986) Microtubule-associated protein tau. A component of Alzheimer paired helical filaments. J Biol Chem 261:6084-6089. Medline

Gunn RN, Lammertsma AA, Hume SP, Cunningham VJ (1997) Parametric imaging of ligand-receptor binding in PET using a simplified reference region model. Neuroimage 6:279-287. CrossRef Medline

Hedden T, Van Dijk KR, Becker JA, Mehta A, Sperling RA, Johnson KA, 
Buckner RL (2009) Disruption of functional connectivity in clinically normal older adults harboring amyloid burden. J Neurosci 29:1268612694. CrossRef Medline

Heggland I, Storkaas IS, Soligard HT, Kobro-Flatmoen A, Witter MP (2015) Stereological estimation of neuron number and plaque load in the hippocampal region of a transgenic rat model of Alzheimer's disease. Eur J Neurosci 41:1245-1262. CrossRef Medline

Iulita MF, Allard S, Richter L, Munter LM, Ducatenzeiler A, Weise C, Do Carmo S, Klein WL, Multhaup G, Cuello AC (2014) Intracellular Abeta pathology and early cognitive impairments in a transgenic rat overexpressing human amyloid precursor protein: a multidimensional study. Acta Neuropathol Commun 2:61. CrossRef Medline

Jack CR Jr, Knopman DS, Jagust WJ, Shaw LM, Aisen PS, Weiner MW, Petersen RC, Trojanowski JQ (2010) Hypothetical model of dynamic biomarkers of the Alzheimer's pathological cascade. Lancet Neurol 9:119-128. CrossRef Medline

Jack CR Jr, Vemuri P, Wiste HJ, Weigand SD, Aisen PS, Trojanowski JQ, Shaw LM, Bernstein MA, Petersen RC, Weiner MW, Knopman DS; Alzheimer's Disease Neuroimaging Initiative (2011) Evidence for ordering of Alzheimer disease biomarkers. Arch Neurol 68:1526-1535. CrossRef Medline

Jack CR Jr, Holtzman DM (2013) Biomarker modeling of Alzheimer's disease. Neuron 80:1347-1358. CrossRef Medline

Jagust W (2016) Is amyloid-beta harmful to the brain? Insights from human imaging studies. Brain 139:23-30. CrossRef Medline

Jansen WJ, et al. (2015) Prevalence of cerebral amyloid pathology in persons without dementia: a meta-analysis. JAMA 313:1924-1938. CrossRef Medline

Kawarabayashi T, Younkin LH, Saido TC, Shoji M, Ashe KH, Younkin SG (2001) Age-dependent changes in brain, CSF, and plasma amyloid (beta) protein in the Tg2576 transgenic mouse model of Alzheimer's disease. J Neurosci 21:372-381. Medline

Killiany RJ, Hyman BT, Gomez-Isla T, Moss MB, Kikinis R, Jolesz F, Tanzi R, Jones K, Albert MS (2002) MRI measures of entorhinal cortex vs hippocampus in preclinical AD. Neurology 58:1188-1196. CrossRef Medline

Klunk WE, et al. (2004) Imaging brain amyloid in Alzheimer's disease with Pittsburgh Compound-B. Ann Neurol 55:306-319. CrossRef Medline

Kosik KS, Orecchio LD, Binder L, Trojanowski JQ, Lee VM, Lee G (1988) Epitopes that span the tau molecule are shared with paired helical filaments. Neuron 1:817-825. CrossRef Medline

Kuntner C, Kesner AL, Bauer M, Kremslehner R, Wanek T, Mandler M, Karch R, Stanek J, Wolf T, Müller M, Langer O (2009) Limitations of small animal PET imaging with [18F]FDDNP and FDG for quantitative studies in a transgenic mouse model of Alzheimer's disease. Mol Imaging Biol 11:236-240. CrossRef Medline

Lacor PN, Buniel MC, Furlow PW, Clemente AS, Velasco PT, Wood M, Viola KL, Klein WL (2007) Abeta oligomer-induced aberrations in synapse composition, shape, and density provide a molecular basis for loss of connectivity in Alzheimer's disease. J Neurosci 27:796-807. CrossRef Medline

Lehéricy S, Baulac M, Chiras J, Piérot L, Martin N, Pillon B, Deweer B, Dubois B, Marsault C (1994) Amygdalohippocampal MR volume measurements in the early stages of Alzheimer disease. AJNR Am J Neuroradiol 15:929-937. Medline

Leon WC, Canneva F, Partridge V, Allard S, Ferretti MT, DeWilde A, Vercauteren F, Atifeh R, Ducatenzeiler A, Klein W, Szyf M, Alhonen L, Cuello AC (2010) A novel transgenic rat model with a full Alzheimer's-like amyloid pathology displays pre-plaque intracellular amyloid-beta-associated cognitive impairment. J Alzheimers Dis 20:113-126. CrossRef Medline

Lu H, Zou Q, Gu H, Raichle ME, Stein EA, Yang Y (2012) Rat brains also have a default mode network. Proc Natl Acad Sci U S A 109:3979-3984. CrossRef Medline

Maeda J, Ji B, Irie T, Tomiyama T, Maruyama M, Okauchi T, Staufenbiel M, Iwata N, Ono M, Saido TC, Suzuki K, Mori H, Higuchi M, Suhara T (2007) Longitudinal, quantitative assessment of amyloid, neuroinflammation, and anti-amyloid treatment in a living mouse model of Alzheimer's disease enabled by positron emission tomography. J Neurosci 27: 10957-10968. CrossRef Medline

Masliah E, Terry RD, DeTeresa RM, Hansen LA (1989) Immunohistochemical quantification of the synapse-related protein synaptophysin in Alzheimer disease. Neurosci Lett 103:234-239. CrossRef Medline

Masters CL, Multhaup G, Simms G, Pottgiesser J, Martins RN, Beyreuther K (1985) Neuronal origin of a cerebral amyloid: neurofibrillary tangles of
Alzheimer's disease contain the same protein as the amyloid of plaque cores and blood vessels. EMBO J 4:2757-2763. Medline

Meguro K, Blaizot X, Kondoh Y, Le Mestric C, Baron JC, Chavoix C (1999) Neocortical and hippocampal glucose hypometabolism following neurotoxic lesions of the entorhinal and perirhinal cortices in the non-human primate as shown by PET: implications for Alzheimer's disease. Brain 122:1519-1531. CrossRef Medline

Minoshima S, Giordani B, Berent S, Frey KA, Foster NL, Kuhl DE (1997) Metabolic reduction in the posterior cingulate cortex in very early Alzheimer's disease. Ann Neurol 42:85-94. CrossRef Medline

Morris R (1984) Developments of a water-maze procedure for studying spatial learning in the rat. J Neurosci Methods 11:47-60. CrossRef Medline

Mufson EJ, Ma SY, Cochran EJ, Bennett DA, Beckett LA, Jaffar S, Saragovi HU, Kordower JH (2000) Loss of nucleus basalis neurons containing trkA immunoreactivity in individuals with mild cognitive impairment and early Alzheimer's disease. J Comp Neurol 427:19-30. CrossRef Medline

Parent M, Shin M, Carmo SD, Aliaga A, Gauthier S, Cuello C, Rosa-Neto P (2013) Resting-state connectivity impairment in a rat model of Alzheimer's disease. Alzheimers Dement 9:P499-P500.

Qi Y, Klyubin I, Harney SC, Hu N, Cullen WK, Grant MK, Steffen J, Wilson EN, Do Carmo S, Remy S, Fuhrmann M, Ashe KH, Cuello AC, Rowan MJ (2014) Longitudinal testing of hippocampal plasticity reveals the onset and maintenance of endogenous human Ass-induced synaptic dysfunction in individual freely behaving pre-plaque transgenic rats: rapid reversal by anti-Ass agents. Acta Neuropathol Commun 2:175. CrossRef Medline

Selkoe DJ (2001) Alzheimer's disease: genes, proteins, and therapy. Physiol Rev 81:741-766. Medline

Shibata M, Yamada S, Kumar SR, Calero M, Bading J, Frangione B, Holtzman DM, Miller CA, Strickland DK, Ghiso J, Zlokovic BV (2000) Clearance of Alzheimer's amyloid-ss(1-40) peptide from brain by LDL receptorrelated protein-1 at the blood-brain barrier. J Clin Invest 106:1489-1499. CrossRef Medline

Silverman DH, et al. (2001) Positron emission tomography in evaluation of dementia: Regional brain metabolism and long-term outcome. JAMA 286:2120-2127. CrossRef Medline

Sperling RA, et al. (2011) Toward defining the preclinical stages of Alzheimer's disease: recommendations from the National Institute on Aging-Alzheimer's Association workgroups on diagnostic guidelines for Alzheimer's disease. Alzheimers Dement 7:280-292. CrossRef Medline

Sperling RA, Laviolette PS, O'Keefe K, O'Brien J, Rentz DM, Pihlajamaki M, Marshall G, Hyman BT, Selkoe DJ, Hedden T, Buckner RL, Becker JA, Johnson KA (2009) Amyloid deposition is associated with impaired default network function in older persons without dementia. Neuron 63: 178-188. CrossRef Medline

Strozyk D, Blennow K, White LR, Launer LJ (2003) CSF Abeta 42 levels correlate with amyloid-neuropathology in a population-based autopsy study. Neurology 60:652-656. CrossRef Medline

Toyama H, Ye D, Ichise M, Liow JS, Cai L, Jacobowitz D, Musachio JL, Hong J, Crescenzo M, Tipre D, Lu JQ, Zoghbi S, Vines DC, Seidel J, Katada K, Green MV, Pike VW, Cohen RM, Innis RB (2005) PET imaging of brain with the beta-amyloid probe, [11C]6-OH-BTA-1, in a transgenic mouse model of Alzheimer's disease. Eur J Nucl Med Mol Imaging 32:593-600. Medline

Walsh DM, Klyubin I, Fadeeva JV, Cullen WK, Anwyl R, Wolfe MS, Rowan MJ, Selkoe DJ (2002) Naturally secreted oligomers of amyloid beta protein potently inhibit hippocampal long-term potentiation in vivo. Nature 416:535-539. CrossRef Medline

Wilson EN, Abela AR, Do Carmo S, Allard S, Marks AR, Welikovitch LA, Ducatenzeiler A, Chudasama Y, Cuello AC (2017) Intraneuronal amyloid beta accumulation disrupts hippocampal CRTC1-dependent gene expression and cognitive function in a rat model of Alzheimer disease. Cereb Cortex 27:1501-1511. CrossRef Medline

Worsley KJ, Marrett S, Neelin P, Vandal AC, Friston KJ, Evans AC (1996) A unified statistical approach for determining significant signals in images of cerebral activation. Hum Brain Mapp 4:58-73. CrossRef Medline

Zimmer ER, Parent MJ, Cuello AC, Gauthier S, Rosa-Neto P (2014) MicroPET imaging and transgenic models: a blueprint for Alzheimer's disease clinical research. Trends Neurosci 37:629-641. CrossRef Medline

Zimmer ER, Parent MJ, Souza DG, Leuzy A, Lecrux C, Kim HI, Gauthier S, Pellerin L, Hamel E, Rosa-Neto P (2017) [18F]FDG PET signal is driven by astroglial glutamate transport. Nat Neurosci 20:393-395. CrossRef 